\title{
Assessment of Incidence, Clinical Profile, Risk Factors and Drug Utilization Pattern in the Management of Gastroenteritis
}

\author{
Battu Rakesh*, Jaladi Himaja
}

Department of Pharmacy Practice, Bharathi College of Pharmacy, Bharathinagara, K. M. Doddi, Mandya, Karnataka, India-571422.

*Corresponding author: Battu Rakesh, Department of Pharmacy Practice, Bharathi College of Pharmacy, Bharathinagara, Mandya, Karnataka-571422 India, E-mail: rakeshjaanu143@ gmail.com

Received: May 10, 2017; Revised: July 25, 2017; Published: August 16, 2017

Copyright: (C2017 Rakesh B, et al. This is an open-access article distributed under the terms of the Creative Commons Attribution License, which permits unrestricted use, distribution, and reproduction in any medium, provided the original author and source are credited. The article has been previewed and authenticated by the Authors before sending the publication for print. The Journal, Editor and the Editorial Board are not entitled or liable to either justify or responsible for inaccurate and misleading data if any. It is the sole responsibility of the Author concerned.

Citation: Rakesh B, Himaja J. Assessment of Incidence, Clinical Profile, Risk Factors and Drug Utilization Pattern in the Management of Gastroenteritis. Int J Pharm Pharmacol 2017; 1: 113. Doi: $\underline{10.31531 / 2581-3080.1000113}$

\begin{abstract}
Background: Acute Gastroenteritis is a common cause of hospitalization in India ranging from mild annoyances to devastating, dehydrating illnesses that can kill within hours. Drug utilization evaluation can be used for the description of drug use pattern; early signals of irrational use of drugs; interventions to improve drug use; quality control cycle; continuous quality improvement.

Objectives:

1. Better understanding the burden and incidence of acute gastroenteritis in adults.

2. Assessment of Clinical Profile and Risk factors for Gastroenteritis.

3. Assessment of Drug utilization pattern in the management of gastroenteritis.

Study Design: Prospective Cross-Sectional study was carried out in the General Medicine Department using a well-designed patient data collection form. All gastroenteritis patients' prescription detail was collected in a specially designed Case Record Form (CRF) for the evaluation of drug prescribing pattern.

Results: Among these 100 patients, male $n=57(57 \%)$ and $n=43$ (43\%) were females. The class of drugs prescribed mostly were antibiotics (100\%), followed by H2 blockers (75\%), and Proton-Pump Inhibitors (25\%), Anti-emetics (89\%), Intravenous fluids (85\%), Prebiotic + Probiotic Combination (84\%), Oral rehydration solution (75\%), Anti-Spasmodic (60\%), Analgesic + Antipyretic (45\%), Antacids (15\%), NSAIDs (15\%) and other miscellaneous drugs for co-morbidities includesGlimepiride + Metformin (6\%), Metformin (3\%), Amlodipine (7\%), Nebulization-Duolin + Budecort (1\%), Cinnarizine (1\%).

Conclusion: Study result shows that male patients (56\%) admitted were more compared to female $(44 \%)$ and may infer that male are more prone to gastroenteritis compared to female gender. Average age of patients found was between 21-30 years, which indicates that the gastroenteritis and related infections may be chronic in this age group because of the westernization and unhygienic outside food.
\end{abstract}


Keywords: Acute Gastroenteritis, Drug Utilization Review, Quality Control Cycle, Westernization

\section{Introduction}

Acute gastrointestinal illnesses are amongst the most common diseases worldwide. In Asia, Africa \& Latin America, acute diarrhoeal illnesses are a leading cause of morbidity in children-with an estimated 1 billion cases per year [1]. Two converging factors highlight the growing need for clear guidelines for the diagnosis and management of infectious diarrhoea. First, there is increasing recognition of a widening array of enteric pathogens associated with illnesses of the gastrointestinal tract. Agents such as enterohemorrhagic E. coli, referred to here as Shiga toxin-producing $E$. coli (STEC), Salmonella, Shigella, Campylobacter jejuni, Clostridium difficile, calici viruses, and other enteric viruses cause 1200 million cases of diarrheal illnesses in the United States each year. Many of these organisms are easily transmitted through food or water or from one person to another, and some are devastating to individuals with compromised immune systems or structural abnormalities of the gastrointestinal tract. With the swift globalization and economic development of our food supply and with assortment of recognized pathogens and diagnostic tools, the challenges of determining optimal, cost-effective means for appropriate diagnosis, clinical management, and public health control of diarrheal illnesses are great [2].

The second factor arises from our having entered an era when health care is increasingly managed with an eye to cost containment. Critical to developing a cost-effective approach to the evaluation and management of infectious diarrhoea is the selective use of available diagnostic methods, therapies, and preventive measures. These must be targeted to the clinical scenarios in which they will yield the greatest benefits, and certain factors must be taken into account: the patient's history, exposure, and immune status, and the nature of the illness: its severity and duration and whether the process is inflammatory or haemorrhagic [2].

From a physician's perspective, there are a number of issues involved in the management of patients with acute gastroenteritis. When a patient presents with symptoms of acute gastroenteritis, the general physician will ask about the patient's history and consider the need for investigations before providing advice on treatment and preventing the spread of infection. They are well placed to provide simple, appropriate, and timely advice to patients about risks and ways to minimise the spread of infection, such as advice on hygiene. Advice on preventing the spread of infection can have an important public health impact, especially if the patient's occupation involves food handling or caring for vulnerable groups, such as children or older people [3].

Adequate fluid and electrolyte replacement and maintenance are key to managing diarrheal illnesses. In established countries, it is a public reason for appearance to general practice or emergency departments and for admission to hospital. Dehydration, which may be associated with electrolyte disturbance and metabolic acidosis, is the most frequent and dangerous complication. Ideal management with oral or intravenous fluids reduces the risk of dehydration and its contrary outcomes. Routine use of antibiotics, anti-diarrhoeal agents, and anti-emetics is not recommended and may cause harm. Prevention is the key to controlling gastroenteritis [4].

\section{Epidemiology and Impact of Gastroenteritis}

Acute gastroenteritis-diarrhoea or vomiting (or both) of more than seven days duration-may be accompanied by fever, abdominal pain, and anorexia. Diarrhoea is the passage of excessively liquid or frequent stools with increased water content. Forms of stooling are different far and wide in young children, and diarrhoea characterizes a change from the norm. Worldwide, 35 billion cases of acute gastroenteritis and nearly 2 million deaths occur each year in children under 5 years. The cost of gastroenteritis to the community is huge but often underestimated if costs to the family, including lost time at work, are not considered $[5,6]$. 


\section{Impact of Inconsistent Testing and Treatment}

The lack of a specific diagnosis can hinder appropriate management and treatment of many infections [7]. Appropriate antimicrobial therapy can shorten illness and reduce morbidity in some bacterial and parasitic infections and can be life-saving in invasive infections [8]. The emergence of microbe strains that are resistant to many commonly used antimicrobial agent's means that treatment failures may become more common and that determinations of antimicrobial susceptibility may be made more often [9]. Knowledge of the local patterns of susceptibility can guide the initial choice of antibiotic but depends on isolation of pathogens from recent clinical specimens. When empirical therapy is undertaken with broad-spectrum antibiotics or when treatment fails because of resistance to the antimicrobial used, it may facilitate the emergence of drug resistance among some bacterial enteric pathogens that spread easily from person to person, such as Shigella species. Empirical treatment also consequences in paths of unnecessary antibiotics. In addition, outcomes of some bacterial diarrheal illnesses may be worsened by the use of antibiotics [10].

The enteric fever (due to Salmonella typhi and Salmonella paratyphi) cause severe illness in young children, characterised by high swinging fever, diarrhoea or constipation, leucopenia, and sometimes central nervous system involvement, including encephalopathy, which is a rare complication of nontyphoid Salmonella infection. Vibrio cholerae toxin causes chloride and water secretion from the small bowel but does not damage the intestinal mucosa; it results in "rice water" stools that have a high sodium content but do not contain blood or white blood cells. Gastroenteritis is acquired by person to person spread or ingestion of contaminated food and drink ("food poisoning"). Undercooked or inappropriately stored cooked or processed meats (chicken, beef and pork) and seafood are common sources of bacterial pathogens. Ingestion of food containing toxins produced by bacterial contaminants (for example, Staphylococcus aureus in ice cream or Bacillus cerus in reheated rice) causes rapid onset of vomiting or diarrhoea (or both). Water may be contaminated with bacteria, viruses, or protozoa including Giardia lamblia, cryptosporidium, Vibrio cholerae and Entamoeba histolytica which causes amoebic dysentery [7].

\section{Complications of Gastroenteritis}

- Dehydration.

- Metabolic acidosis.

- Electrolyte disturbance (hypernatremia, hyponatremia, hypokalemia).

- Carbohydrate (lactose, glucose) intolerance.

- Susceptibility to reinfection.

- Development of food (cow's milk, soy protein) intolerance.

- Hemolytic uremic syndrome.

- Iatrogenic complications (due to inappropriate composition or amount of intravenous fluids).

- Death [11].

A lot of population are getting infected with gastroenteritis. Hence it became very essential to spread a thorough awareness among patients in relation to medication and disease itself [9]. So, evaluation of drug utilization pattern in gastroenteritis will provide a powerful tool in order to find depth of awareness in patients and physician. The technique of Drug Utilization Review (DUR) can provide useful means of determining whether drug use is as appropriate in treatment of individual patients. It can be used for the description of drug use pattern; early signals of irrational use of drugs; interventions to improve drug use; quality control cycle; continuous quality improvement [13].

According to World Health Organization (WHO), Drug Utilization Evaluation (DUE) is a system of on-going, systematic, criteria-based evaluation of drug use that will help ensure that medicines are used appropriately (at the individual patient level). If therapy is deemed to be inappropriate, 
interventions with providers or patients will be necessary to optimize drug therapy. A DUE is drug-or disease-specific plus can be organized so that it will evaluate the authentic process of prescribing, dispensing or administering a drug (indications, dose, drug interactions, etc.). DUE is the same as Drug Utilization Review (DUR) and terms are used synonymously [5]. Depraved prescribing practices lead to ineffective and insecure treatment, exacerbation or perpetuation of sickness, suffering and destruction to the patient and higher costs. Monitoring of prescriptions and drug utilization studies can identify the problems and provide feedback to prescribers to create awareness about irrational use of drugs [14].

The goal of a DUE or MUE is to promote optimal medication therapy and ensure that drug therapy meets current standards of care. Additional objectives may include:

- Creating guidelines (criteria) for appropriate drug utilization.

- Evaluating the effectiveness of medication therapy.

- Enhancing responsibility/accountability in the medicine use process.

- Controlling medicine cost.

- Preventing medication related problems, for example adverse drug reactions, treatment failures, over-use, under-use, incorrect doses and non-formulary medicine use.

- Identifying areas in which further information and education may be needed by health-care providers [15].

Drug Utilization Review is increasingly used in the era of cost constraints and quality assurance [5]. It is an essential part of pharmacoepidemiological studies; they together provide a proper understanding of usage pattern of drugs, quality and efficiency of drug use, determinants (social status of patient, therapeutic decisions of prescriber) and the outcomes of the drug use.

DURs involve a wide-ranging review of patients' treatment and prescription data in advance, during, and after dispensing to ensure appropriate medication decision making and positive patient outcomes. DURs are classified into three categories:
- Prospective - evaluation of a patient's therapy before medication is dispensed.

- Concurrent - on-going monitoring of drug therapy during the course of treatment.

- Retrospective - review of therapy after the patient has received the medication.

\section{Importance of Drug Utilization Review}

DUR programs show a vital character in facilitating managed health care systems comprehend, infer, and develop the prescribing, administration, and use of medications. Pharmacists play a key role in this process because of their expertise in the area of pharmaceutical care. DURs afford the managed care pharmacist the opportunity to identify trends in prescribing within groups of patients such as those with asthma, diabetes, or high blood pressure. Pharmacists can then, in collaboration with other members of the health care team, initiate action to improve drug therapy for both individual patients and covered populations. DURs serve as a worth of enlightening the superiority of patient care, augmenting therapeutic outcomes, and reducing incongruous pharmaceutical expenditures, thus reducing overall health care costs. Hence Drug utilization studies provide useful insights into current prescribing practices and can thus help in reforming and updating practices in clinical medicine and pharmacotherapy [11].

\section{Aims and Objectives}

- Better understanding the burden and incidence of acute gastroenteritis in adults.

- Assessment of Clinical Profile and Risk factors for Gastroenteritis.

- Assessment of Drug utilization pattern in the management of gastroenteritis.

\section{Materials and Methodology}

A Prospective, Cross Sectional study was carried out in various units such as Intensive Critical Care Unit (ICCU), Respiratory Intensive Care Unit (RICU), Medical Intensive Care Unit (MICU), Medical wards (Male and Female) of the department of general medicine in a tertiary care hospital, Karnataka, India. The essential data for the Cross-Sectional study was collected from patient case files using a well- 
designed patient data collection form. A total of 100 gastroenteritis patient's files were screened and data was analysed.

\section{Inclusion Criteria}

- Patients of either sex who are $\geq 20$ years of age.

- Patients who are diagnosed as suffering from gastroenteritis.

\section{Exclusion Criteria}

- All pregnant women and lactating mothers, patients in other wards and departments of the hospital.

- Individuals who are not willing to be a part of the study.

- All out patients in Out Patient Department.

- Padiatrics.

- Seriously and mentally ill patients.

\section{Source of Data}

Patient files were screened for the demographic information, laboratory investigations, diagnosis and the medication prescribed each day. A suitably designed patient data collection form was used to record all the necessary data. It also includes the present complaints of the patient, past medical history, past medication history, family history, social history (including diet, alcohol/smoking habits, sleep, bowel and bladder, appetite, exercise habit), physical examination, systemic examination etc.

\section{Procedure}

All gastroenteritis patients' prescription detail was collected in a specially designed case record form (CRF) for the evaluation of drug prescribing pattern. The medications prescribed for treating gastroenteritis were analysed. The parameters noted were: Name of the drug, Dosage form, Route, Frequency and Duration of administration, Generic/Brand name and the number of drugs received by the individual patients during their hospital stay. The information leaflet containing details of gastroenteritis, use of medications, and life style modifications is prepared after consulting with physicians and pharmacists and issued to patients in their vernacular language.

\section{Statistical Analysis}

Rakesh B, et al. Int J Pharm Pharmacol
After acquiring the details, we have performed various analyses in the collected data. The analysis was based on patient age, gender, social history, drug utilisation pattern etc. Collected information was analysed using Microsoft Office (MS-Word and Excel) 2010. Descriptive data analysis has been performed in the form of percentage of demographic variables and drug therapy and related issues were shown as various tables and graphs for better understanding of data. For the analysis of the results, simple percentage calculations were used to arrive at a conclusion of our study.

A total number of 100 case sheets of gastroenteritis patients admitted to hospital were analysed. Among these 100 patients, majority of the patients were male $n=57(57 \%)$ and $n=43(43 \%)$ were females (Figure 1).

Out of 100 patients, 80 patients were having Acute Gastroenteritis with moderate dehydration, 20 patients are with comorbidities which includes- 9 cases of Acute Gastroenteritis with Type-2 Diabetes Mellitus, 7 cases of Acute Gastroenteritis + Type-2 Diabetes Mellitus + Hypertension, 1 patient with Acute Gastroenteritis with Vertigo, 1 patient with Acute Gastroenteritis + COPD, 2 Patients with Acute Gastroenteritis + Malaria.

The patients were divided into 7 groups based on their age group (Figure 2, Table 2) 20-30 years of age.

1. 31- 40 years of age.

2. 41-50 years of age.

3. 51-60 years of age.

4. 61-70 years of age.

5. 71-80 years of age.

6. 81-90 years of age.

\section{Patient Distribution Based on Diet History}

Based on the diet such as homemade and outside, 100 patients have been divided. 51 patients $(51 \%)$ were taking home food, 35 patients $(35 \%)$ were taking outside food, and 14 patients $(14 \%)$ were taking Home Food + Outside Food (Figure 3, Table 3).

\section{Patient Distribution Based on Clinical Profile}

Out of 100 patients, 39 Patients (39\%) has 
shown symptoms such as Vomiting + Diarrhoea + Abdominal Pain + Fever, 4 Patients $(4 \%)$ presented with Diarhoea, 30 Patients $(30 \%)$ presented with Vomiting + Diarrhoea, 1 Patient (1\%) presented with Diarrhoea + Fever, 10 Patients (10\%) presented with Diarrhoea + Abdominal Pain, 11 Patients $(11 \%)$ presented with Vomiting + Diarrhoea + Abdominal Pain, 5 Patients (5\%) presented with Fever + Vomiting + Epigastric Pain (Figure 4, Table 4).

\section{Drug Utilization Pattern in Acute Gastroenteritis}

Among 100 prescriptions, it has been observed that all the prescriptions contained more than 5 drugs. The prescription of more than 5 drugs for one patient per prescription may be attributed to the possibility polypharmacy which in turn leads to drug interaction and adverse drug reactions.

In Gastroenteritis the class of drugs prescribed mostly were antibiotics (100\%), followed by $\mathrm{H}_{2}$ blockers $(75 \%)$, and Proton-Pump Inhibitors (25\%), Anti-emetics (89\%), Intravenous fluids $(85 \%)$, Prebiotic + Probiotic $(84 \%)$, oral rehydration solution (75\%), Anti-Spasmodic (60\%), Analgesic + Antipyretic (45\%), Antacids (15\%), NSAIDs (15\%), and other miscellaneous drugs for co-morbidities includes-Glimepiride + Metformin (6\%), Metformin (3\%), Amlodipine (7\%), Nebulization-Duolin + Budecort (1\%), Cinnarizine (1\%) (Figure 5).

\section{Patient Distribution Based on Antibiotics}

Among 100 patients, various patients received different types of antibiotics as an empirical therapy for the management of Acute Gastroenteritis- Cefotaxim (51\%), Ceftriaxone (45\%), Amikacin (15\%), Metronidazole + Ciprofloxacin (85\%), Ciprofloxacin (7\%), Metronidazole (5\%), Ciprofloxacin + Ceftriaxone (7\%), Metronidazole + Ceftriaxone $(5 \%)$, Amikacin + Cefotaxim (7\%) (Figure 6).

\section{Miscellaneous Drugs}

Out of 102 patients apart from main therapy, adjunct therapy for gastroenteritis includes$\mathrm{H}_{2}$ blockers (75\%), and Proton-Pump Inhibitors (25\%), Anti-emetics (89\%),
Intravenous fluids (85\%), Prebiotic+ Probiotic $(84 \%)$, oral rehydration solution (75\%), Anti-Spasmodic (60\%), Analgesic + Antipyretic (45\%), Antacids (15\%), NSAIDs $(15 \%)$, and other miscellaneous drugs for comorbidities includes- Glimepiride + Metformin (6\%), Metformin (3\%), Amlodipine (7\%), Nebulization-Duolin + Budecort (1\%), Cinnarizine (1\%) (Figure 7).

\section{Discussion}

Better health care services will have a positive impact on health care system. A lot of population are suffering from gastroenteritis. Hence it became very essential to spread a thorough awareness among patients in relation to medication and disease itself. So, evaluation of drug utilisation pattern gastroenteritis will provide a powerful tool in order to find depth of awareness in patients and physician. A prescription-based study is considered one of the scientific methods to evaluate the rationality of the prescription. Drug utilization study is a crucial fragment of pharmacoepidemiology as it describes the extent, nature and determinants of drug exposure. Drug use is a complex process. In any country, a large number of socio-cultural factors contribute to the ways drugs [16].

Many studies were conducted to evaluate the value addition of drug therapy management into the patient care in critical care setting, but gastroenteritis patient(s) were rarely focused as the chances of readmission in hospitals and number of days of hospitalisation is found more in infected cases of gastroenteritis, so this study aimed to focus on analysis of prevalence, risk factors and drug utilization pattern in the management of acute gastroenteritis in a tertiary care hospital. A drug therapy plan may require discontinuation or addition of a drug as well dosage adjustments and thus requires more complex decision-making skills. Determining whether a patient actually requires drug therapy is probably the most intricate problem to identify because the outcomes of the patient's drug therapy depends upon the patient's social history as well pathophysiology and pharmacotherapeutics, which is altered due to disease conditions. 
Drug therapy management is an effective mechanism to facilitate assessment of the indications, effectiveness and safety of drug products, especially in patients who are using multiple medications due to concurrent diseases (co-morbidities). Most number of studies has shown that many hospital admissions and readmissions are due to co-morbid conditions, adverse drug events, medication errors or suboptimal prescribing. Study result shows that male patients $(56 \%)$ admitted were more compared to female $(44 \%)$ and may infer that male are more prone to gastroenteritis compared to female gender. Average age of patients found was between 21-30 years, which indicates that the gastroenteritis and related infections may be chronic in this age group because of the westernization and unhygienic outside food [17].

Majority of the cases in acute gastroenteritis and its increased prevalence is mainly due to the sedentary lifestyle, unhealthy/unhygienic outside food which may be contaminated are potent risk factors for gastroenteritis and consequently producing its symptoms and in severe cases it leads to death of patient due to severe dehydration. Lower socioeconomic classes from both urban and rural areas are the sufferers.

Based on the diet such as homemade and outside, 100 patients have been divided. 51 patients $(51 \%)$ were taking home food, 35 patients $(35 \%)$ were taking outside food, and 14 patients $(14 \%)$ were taking Home Food + Outside Food.

Among 100 patients, various patients received different types of antibiotics as an empirical therapy for the management of Acute Gastroenteritis in adults - Cefotaxim (51\%), Ceftriaxone (45\%), Amikacin (15\%), Metronidazole + Ciprofloxacin (85\%), Ciprofloxacin (7\%), Metronidazole (5\%), Ciprofloxacin + Ceftriaxone $(7 \%)$, Metronidazole + Ceftriaxone (5\%), Amikacin + Cefotaxim (7\%).

Clinical pharmacists play a significant role in critical care units for the better treatment outcomes in critically ill patients by deciding right choice of drug and right doses of medications depending on the patient condition. Medication therapy management becomes more important for patients in critical care units, as they require an extra amount of care and consideration as a consequence of complicated and extensive medication regimens.

\section{Conclusion}

In our study, we observed that the incidence of gastroenteritis was more common in males when compared to females. Majority of the patients were from the age group of 21-30 years. Gastroenteritis is more prominent in people taking unhealthy/contaminated food when compared to hygienic/uncontaminated food. Most of the patients were prescribed with multiple drug therapy out of which intravenous route was the most preferred one.

The intravenous route is the most preferred route because in gastroenteritis oral drug therapy is not sufficient/impossible due to vomiting and it significantly improves the therapeutic effectiveness and minimizes the systemic side effect.

Study clearly shows overuse and inappropriate choice of antibiotics for the treatment of acute, uncomplicated gastroenteritis which are mainly due to virus and do not require antibiotic treatment. Results of the study warrant interventional strategies to promote rational use of antibiotics to decrease the overgrowing threat of antibiotic resistance. Minimizing inappropriate antibiotic use is thus the best way to control resistance.

From our study, we found that the total control of gastroenteritis was achieved. The majority of patients had intermittent exacerbations of symptoms. The pattern of drug utilization is adequate.

Drug therapy should be aimed at treating both the comorbidities and existing conditions rather either alone. The pharmacist is required to put certain steps in order to improve the awareness among the prescribers and patients as he is a person in close contact with prescribers and patients.

\section{Limitations of the Study}


- The external validity of the study may have also been limited by the small sample size, short study duration and follow-up.

- This is the first type of attempt to provide drug utilization evaluation in our setting. Monitoring patients for longer period would reflect more accurate profile of the natural time frame of the medication views. Other chronic diseases can also be managed in a similar manner.

- Establishing the interventions in the form of educational programs can improve the healthy well-being of the patient and decreases the risk of gastroenteritis complications and also improves the overall drug therapy of the patient.

\section{Future Scope of the Study}

- This study may be helpful in identifying the new concept of drug therapy management of patients in different disease conditions in critical care and also introduce the new concept of drug therapy management in Karnataka state, India.

- Pharmacoeconomic evaluation studies of medication therapy can be done to assess the burden of gastroenteritis and related infections in the population to avoid unnecessary costs of medication.

- Pharmacoepidemiological studies can be done to study the uses and effects of drugs in well-defined populations.

\section{Conflict of Interest and Financial Support}

There is no conflict of interest in the study. The authors have no financial support.

\section{References}

1. Butterton J R, Cadderwood SB, Braunwald $F$, et al. Acute Infectious Diarrhoeal Diseases \& Bacterial Food Poisoning. Harrison's Principles of Internal Medicine. McGraw Hill, 2003; $16^{\text {th }}$ edition, 754.

2. Guerrant RL, Gilder TV, Steiner TS, et al. Practice Guidelines for the Management of Infectious Diarrhoea. IDSA Guidelines. Clin Inf Dis 2001; 32: 331-350.

3. Bennett RG, Greenough WB. Approach to acute diarrhea in the elderly. Gastroenterol Clin North Am 1993; 22: 517-533.

4. Tham EB, Nathan R, Davidson GP, et al.
Bowel habits of healthy Australian children aged 02 years. J Paediatr Child Health 1996; 32: 5047.

5. Ruben AR, Fisher DA. The casemix system of hospital funding can further disadvantage Aboriginal children. Med J Aust 1998; 169: S 610.

6. Kirkwood CD, Bogdanovic-Sakran N, Cannan D, et al. National rotavirus surveillance program annual report 20042005. Commun Dis Intell 2006; 30: 133136.

7. US Food and Drug Administration Center for Food Safety and Applied Nutrition. Bacterial explanations. Bacterial testing and analysis at FPL. www.fplabs.com/bactlist.htm.

8. Elliott E, Browne R. Hemolytic uremic syndrome. Problems in child and adolescent medicine. USA: Elsevier 2005; 35: 31030.

9. Institute of Medicine. Emerging infections: microbial threats to health in the United States. Washington, DC: National Academy Press, 1992.

10. Hines J, Nachamkin I. Effective use of the clinical microbiology laboratory for diagnosing diarrheal diseases. Clin Infect Dis 1996; 23: 1292-1301.

11. Elliott EJ. Acute gastroenteritis in children. Clinical Review. BMJ 2007; 334: 35-40.

12. Shimpi RD, Salunkhe PS, Bavaskar SR, et al. Drug utilization evaluation and prescription monitoring in asthmatic patients, Int $\mathbf{J}$ of Phar and Bio Sci. 2012; 2:117-122.

13. Sunil S, Gigi A, Hepzhiba P, et al. Drug utilization evaluation in chronic obstructive pulmonary disease patients-A prospective study. World J Phar Pharmac Sci 2015; 5: 1133-1143.

14. Sharma P, Kapoor B. Study of prescribing pattern for rational drug therapy; from the Department of Pharmacology, Government Medical College, Jammu (J\&K) India. 2003; 5:107-109.

15. http://apps.who.int/medicinedocs/en/d/Js48 82e/8.5.html

16. Sachdeva PD, Patel BG. Drug utilization studies-Scope and future perspectives. Int $\mathrm{J}$ Pharm Bio Res 2010; 1: 11-17.

17. Hurd S. The impact of COPD in lung health worldwide: Epidemiology and incidence. Chest 2000; 117: 1S-4S. 
Table 1: Socio-Demographic and Disease Parameters

\begin{tabular}{|c|c|c|c|c|c|}
\hline \multicolumn{6}{|c|}{ Socio-Demographic and Clinical Parameters } \\
\hline \multirow[t]{3}{*}{1} & \multirow{3}{*}{\multicolumn{3}{|c|}{$\begin{array}{l}\text { Gender } \\
\text { Male } \\
\text { Female }\end{array}$}} & No. of Patients & Percentage (\%) \\
\hline & & & & 57 & $57 \%$ \\
\hline & & & & 43 & $43 \%$ \\
\hline \multirow[t]{4}{*}{2} & \multicolumn{3}{|c|}{ Diet History } & & \\
\hline & \multicolumn{3}{|c|}{ Home Food } & 51 & $51 \%$ \\
\hline & \multicolumn{3}{|c|}{ Outside Food } & 35 & $35 \%$ \\
\hline & \multicolumn{3}{|c|}{ Home Food + Outside Food } & 14 & $14 \%$ \\
\hline \multirow[t]{10}{*}{3} & \multirow{10}{*}{\multicolumn{3}{|c|}{$\begin{array}{l}\text { Clinical Profile } \\
\text { Vomiting }+ \text { Diarrhoea }+ \text { Abdominal Pain }+ \\
\text { Fever } \\
\text { Diarrhoea } \\
\text { Vomiting + Diarrhoea } \\
\text { Diarrhoea + Fever } \\
\text { Diarrhoea + Abdominal Pain } \\
\text { Vomiting + Diarrhoea + Abdominal Pain } \\
\text { Fever + Vomiting + Epigastric Pain }\end{array}$}} & & \\
\hline & & & & & \\
\hline & & & & 39 & \\
\hline & & & & 4 & $4 \%$ \\
\hline & & & & 30 & $30 \%$ \\
\hline & & & & 1 & $1 \%$ \\
\hline & & & & 10 & $10 \%$ \\
\hline & & & & 11 & $11 \%$ \\
\hline & & & & & \\
\hline & & & & & \\
\hline \multirow[t]{10}{*}{4} & \multicolumn{3}{|c|}{ Disease Condition } & & \\
\hline & \multirow{2}{*}{\multicolumn{3}{|c|}{ Acute Gastroenteritis with Moderate }} & & \\
\hline & & & & & \\
\hline & \multirow{2}{*}{\multicolumn{3}{|c|}{$\begin{array}{l}\text { Acute Gastroenteritis }+ \text { Type-2 Diabetes } \\
\text { Mellitus }\end{array}$}} & & \\
\hline & & & & & \\
\hline & \multirow{2}{*}{\multicolumn{3}{|c|}{$\begin{array}{l}\text { Acute Gastroenteritis }+ \text { Type- } 2 \text { DM }+ \\
\text { Hypertension }\end{array}$}} & 7 & $1 \%$ \\
\hline & & & & & \\
\hline & \multicolumn{3}{|c|}{ Acute Gastroenteritis + Vertigo } & 1 & $1 \%$ \\
\hline & \multicolumn{3}{|c|}{ Acute Gastroenteritis + COPD } & 1 & $1 \%$ \\
\hline & \multicolumn{3}{|c|}{ Acute Gastroenteritis+ Malaria. } & 2 & $2 \%$ \\
\hline
\end{tabular}


Table 2: Distribution of Patients Based on Age Group and Gender

\begin{tabular}{|c|c|c|c|}
\hline Age Group (Year) & Male & Female & Percentage (\%) \\
\hline $20-30$ & 23 & 15 & $38 \%$ \\
\hline $31-40$ & 12 & 10 & $22 \%$ \\
\hline $41-50$ & 8 & 4 & $12 \%$ \\
\hline $51-60$ & 4 & 5 & $09 \%$ \\
\hline $61-70$ & 4 & 3 & $07 \%$ \\
\hline $71-80$ & 3 & 4 & $07 \%$ \\
\hline $81-90$ & 2 & 3 & $05 \%$ \\
\hline Total & 56 & 44 & $100 \%$ \\
\hline
\end{tabular}

Table 3: Distribution of Patients Based on Place of Food Consumption

\begin{tabular}{|c|c|c|}
\hline Location & No. of Patients & Percentage \\
\hline Home Food & 51 & $51 \%$ \\
\hline Outside Food & 35 & $35 \%$ \\
\hline Home Food + Outside Food & 14 & $14 \%$ \\
\hline Total & $\mathbf{1 0 0}$ & $\mathbf{1 0 0 \%}$ \\
\hline
\end{tabular}

Table 4: Patient Distribution Based on Clinical Profile

\begin{tabular}{|l|c|c|}
\hline \multicolumn{1}{|c|}{ Symptoms } & No. of Patients & Percentage \\
\hline Vomiting + Diarrhoea + Abdominal Pain + & 39 & $39 \%$ \\
Fever & 4 & $4 \%$ \\
Diarrhoea & 30 & $30 \%$ \\
Vomiting + Diarrhoea & 1 & $1 \%$ \\
Diarrhoea + Fever & 10 & $10 \%$ \\
Diarrhoea + Abdominal Pain & 11 & $11 \%$ \\
Vomiting + Diarrhoea + Abdominal Pain & 5 & $5 \%$ \\
Fever + Vomiting + Epigastric Pain & & \\
\hline
\end{tabular}




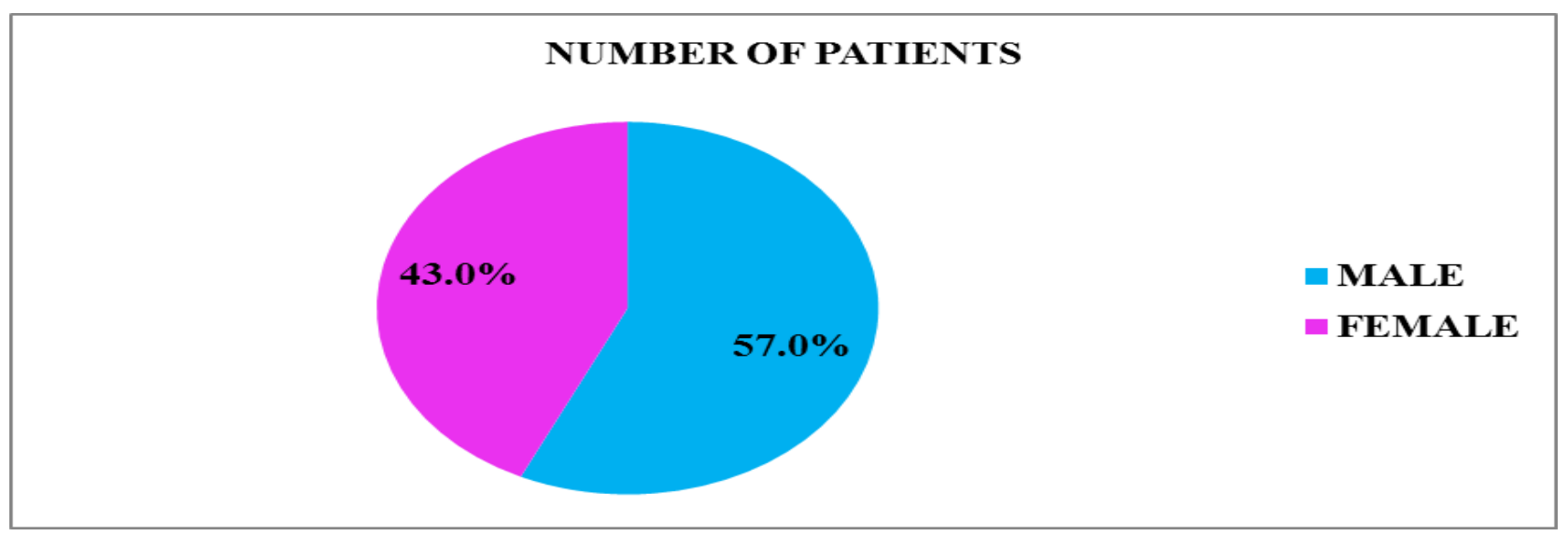

Figure 1: Gender Wise Distribution of Gastroenteritis patients

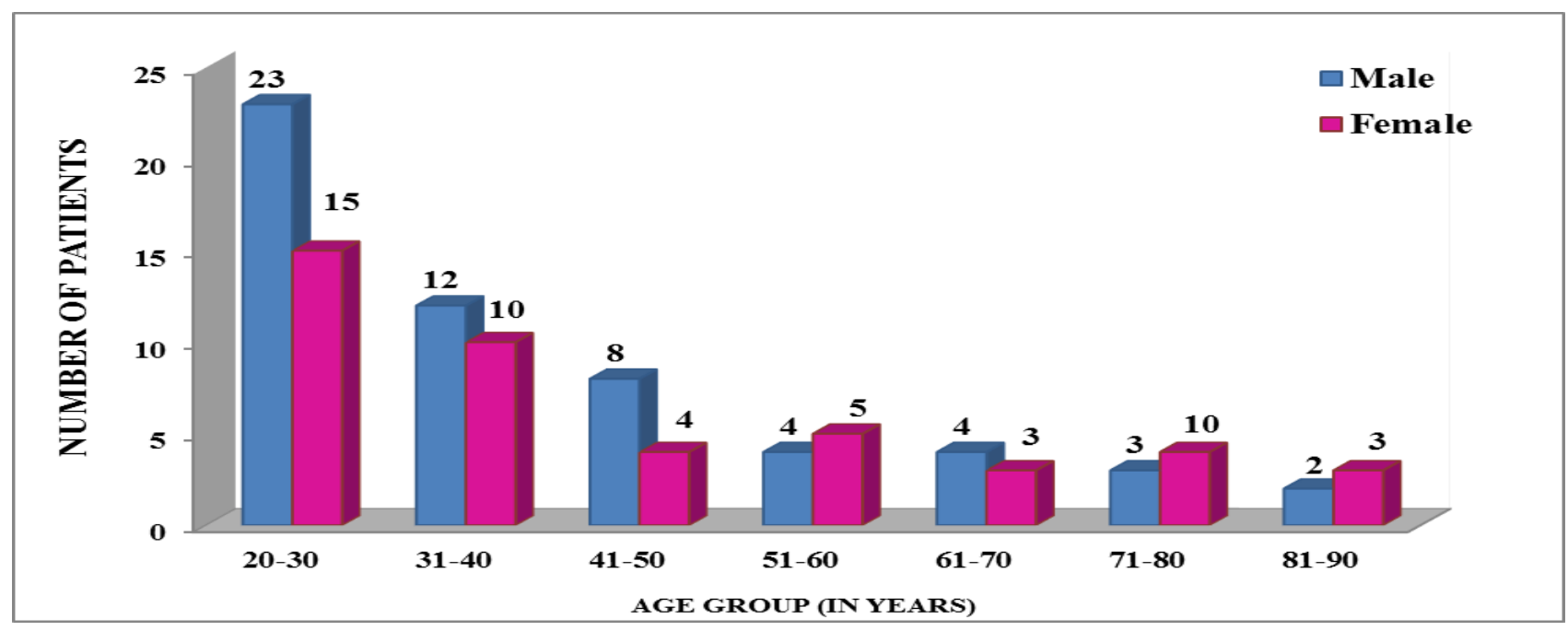

Figure 2: Distribution of Patients Based on Age Group and Gender

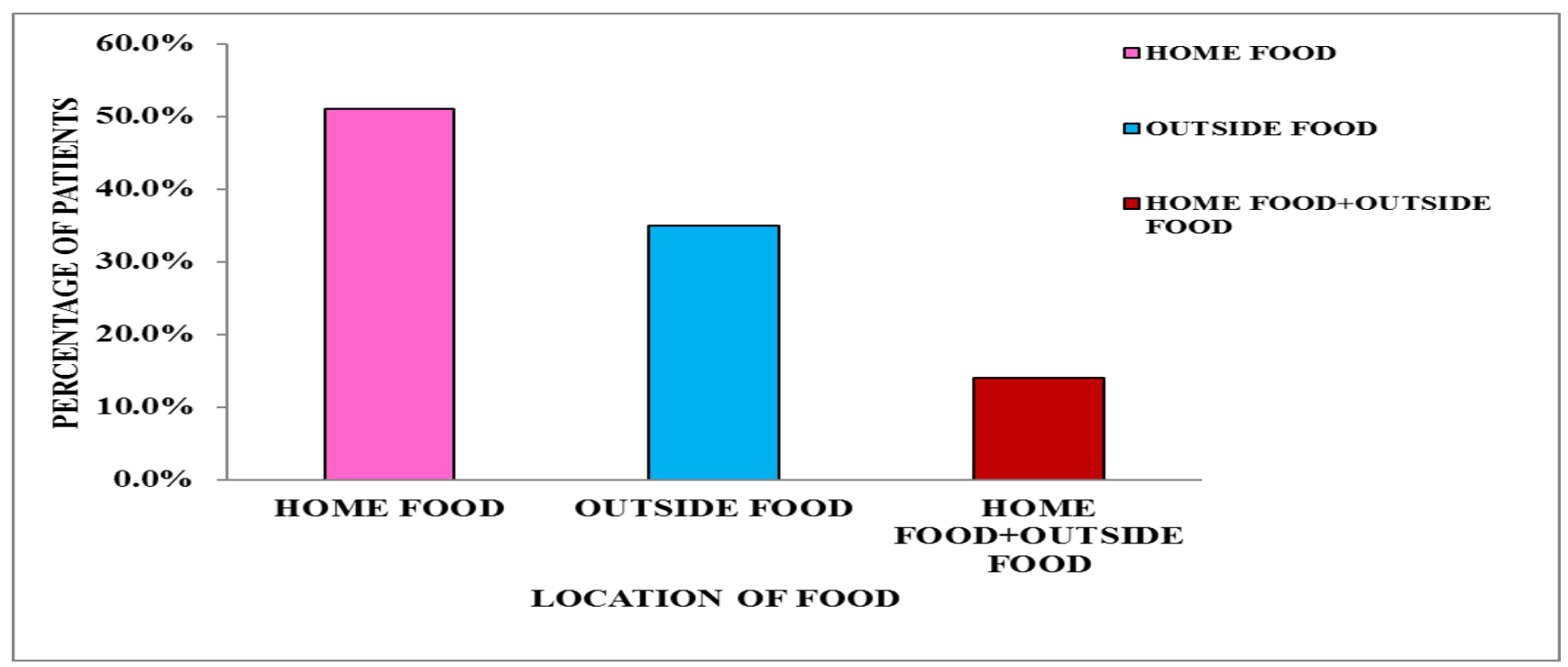

Figure 3: Distribution of Patients Based on Place of Food Consumption 


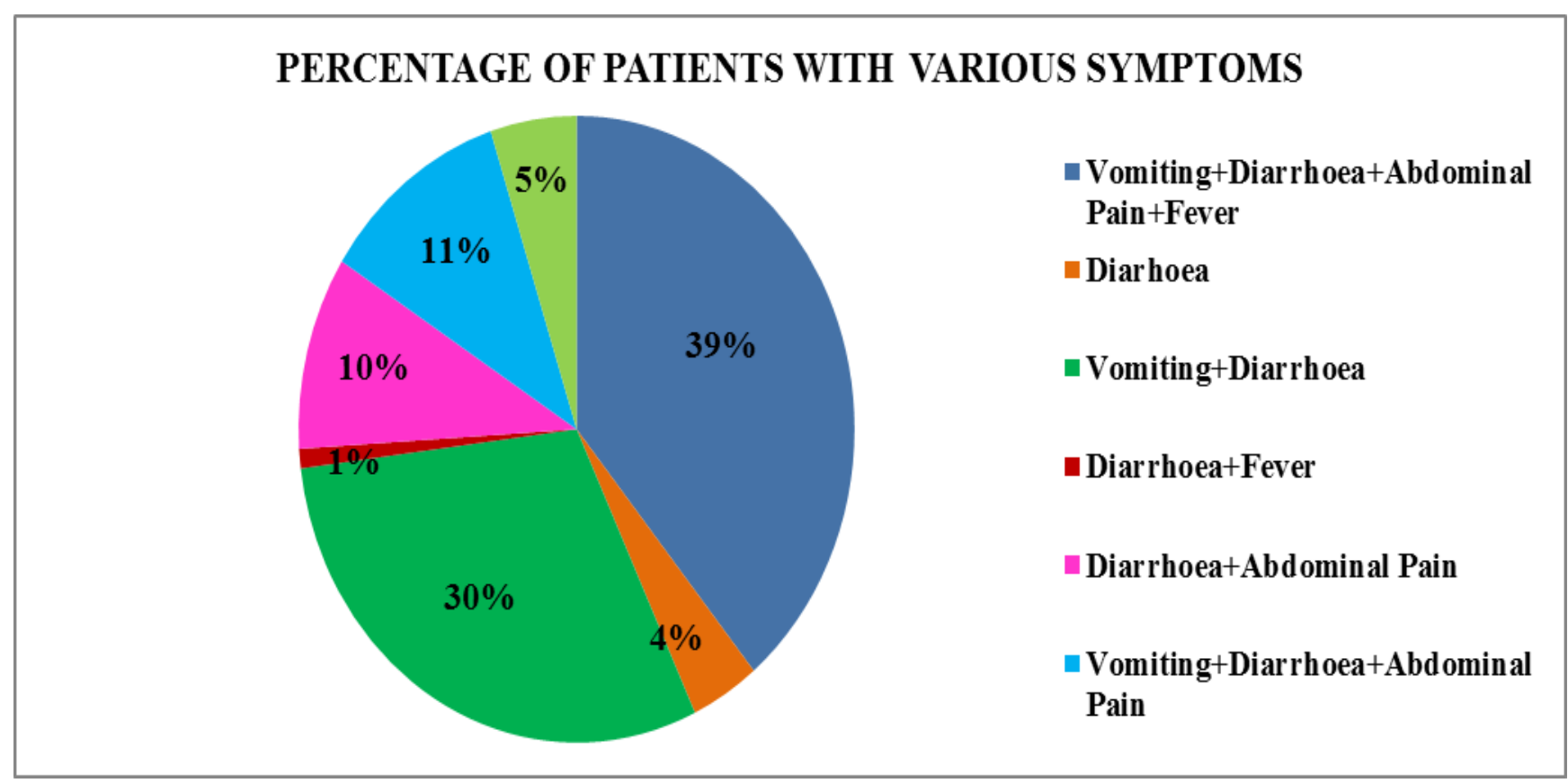

Figure 4: Patient Distribution Based on Symptoms

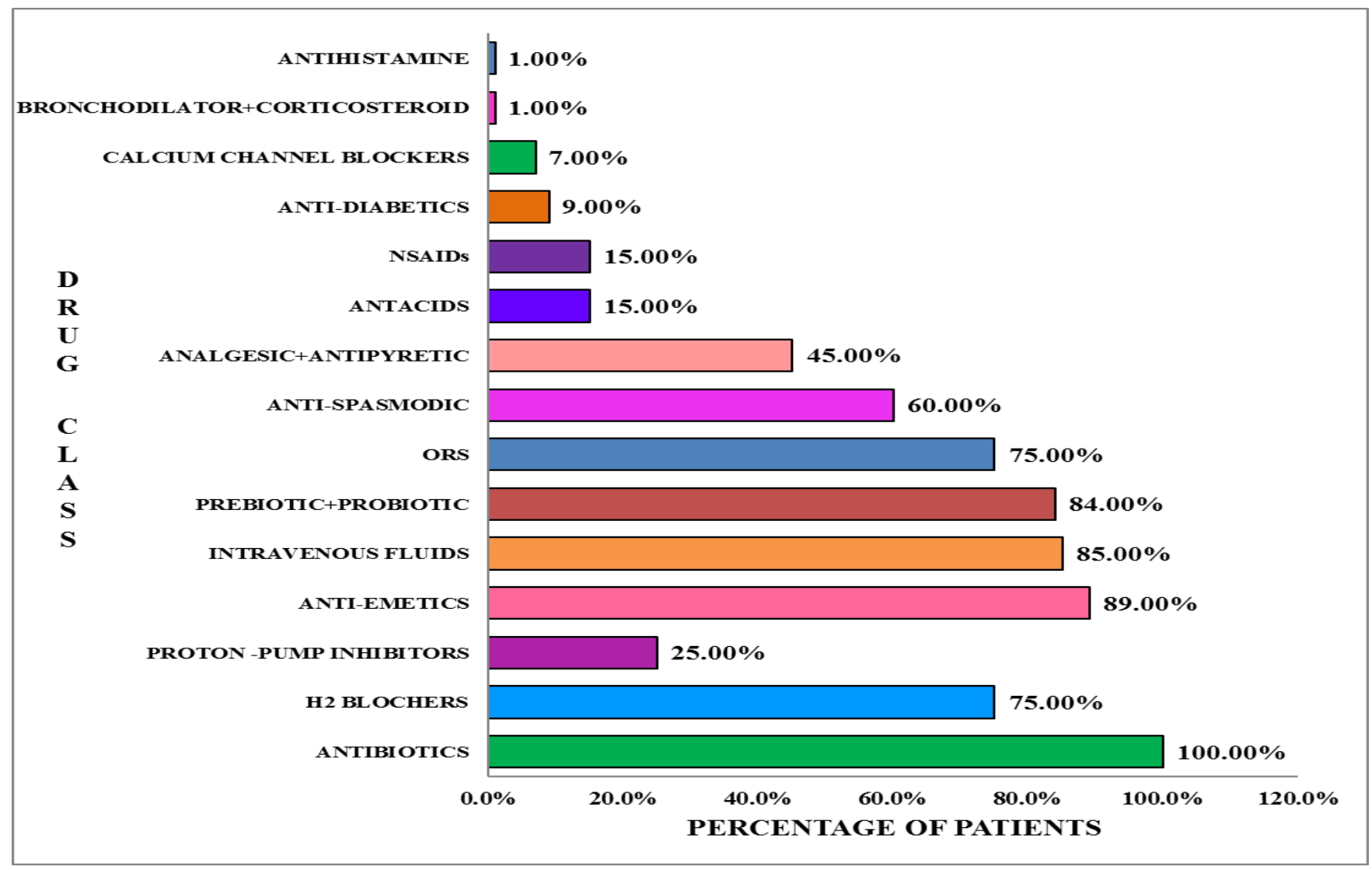

Figure 5: Percentage of Drugs Prescribed by Class 


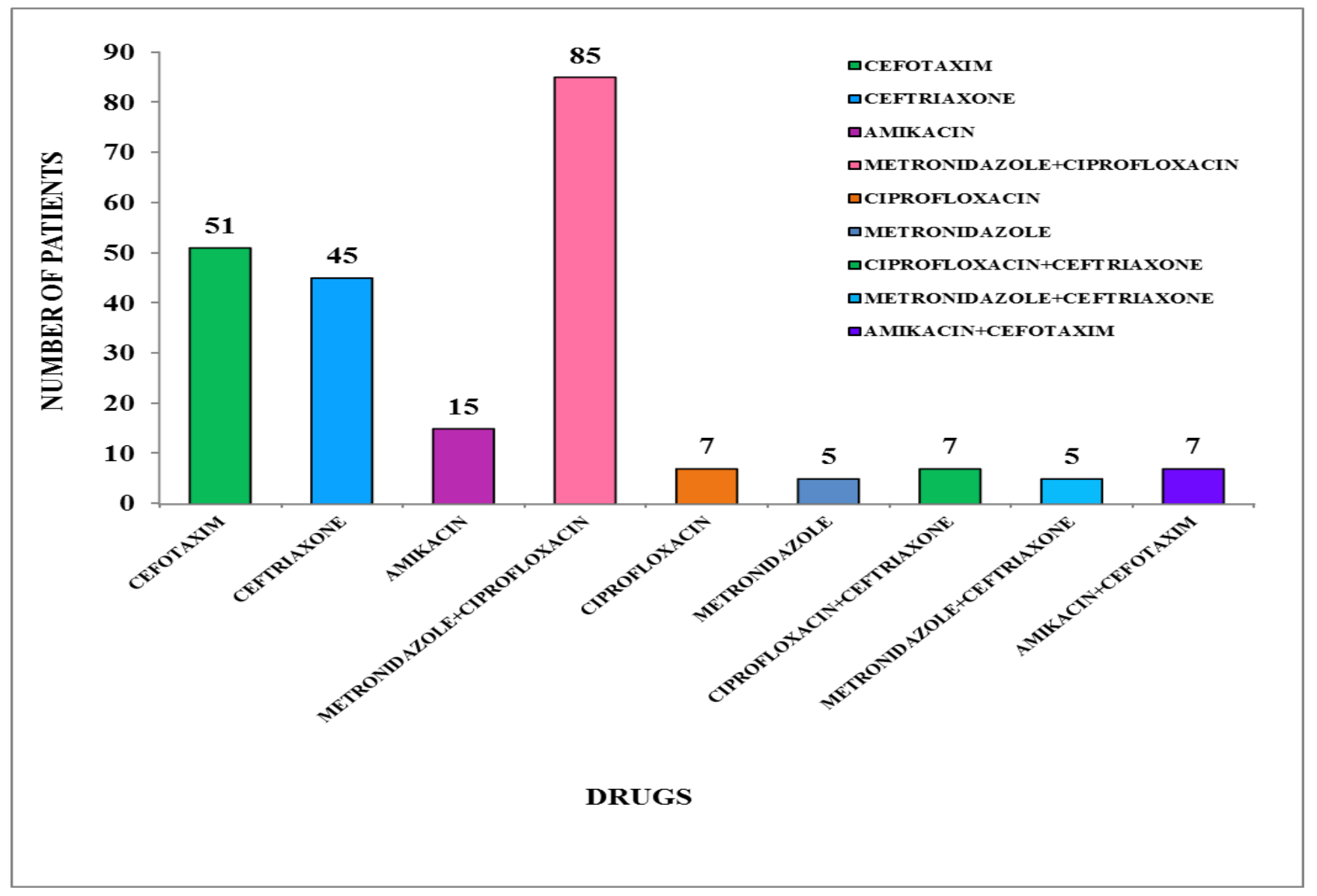

Figure 6: Patient distribution based on Type of Antibiotic Received

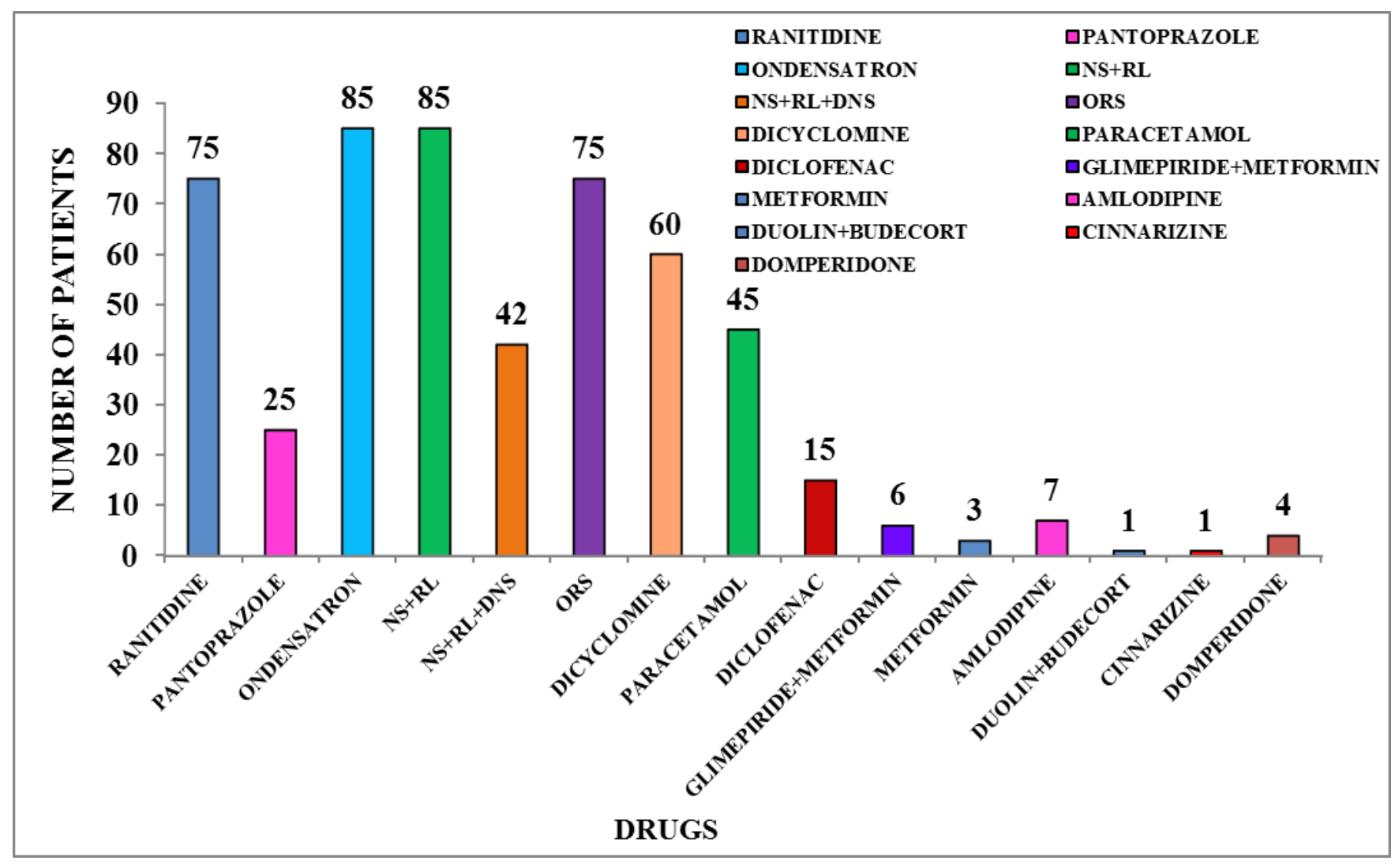


This manuscript was peer-reviewed

Mode of Review: Single-blinded

Editor: Dr. Mohamed Azmi Ahmad Hassali

International Journal of Pharmaceutics and Pharmacology is an open access, peer reviewed journal published by Edwiser International.

Submit your valuable manuscript at-

editor.ijpp@edwiserinternational.com

submit.manuscript@edwiserinternational.com

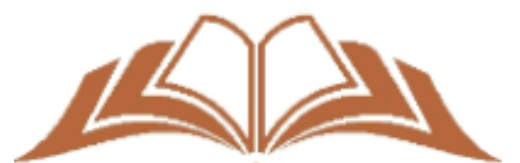

$\mathrm{E} D \mathrm{~W} \theta \mathrm{\theta} \mathrm{ER}$
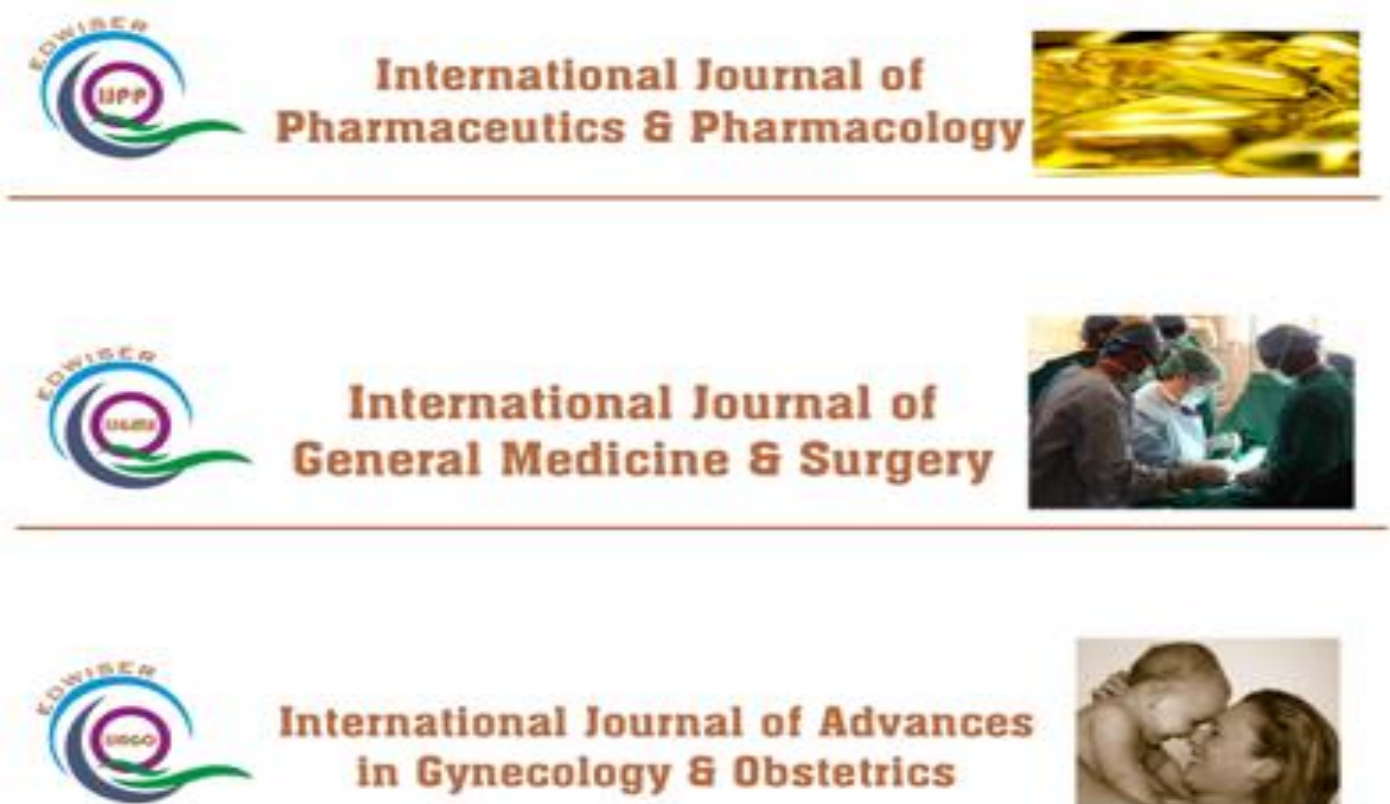

International Journal of Advances

in Gynecology \& Obstetrics
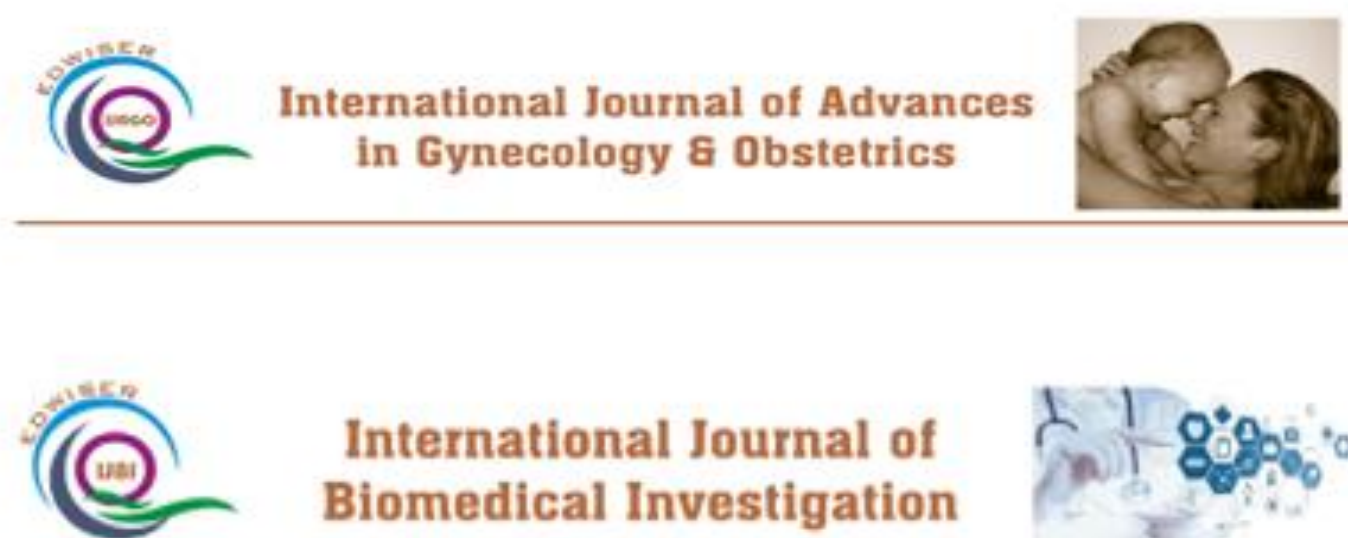

International Journal of Biomedical Investigation
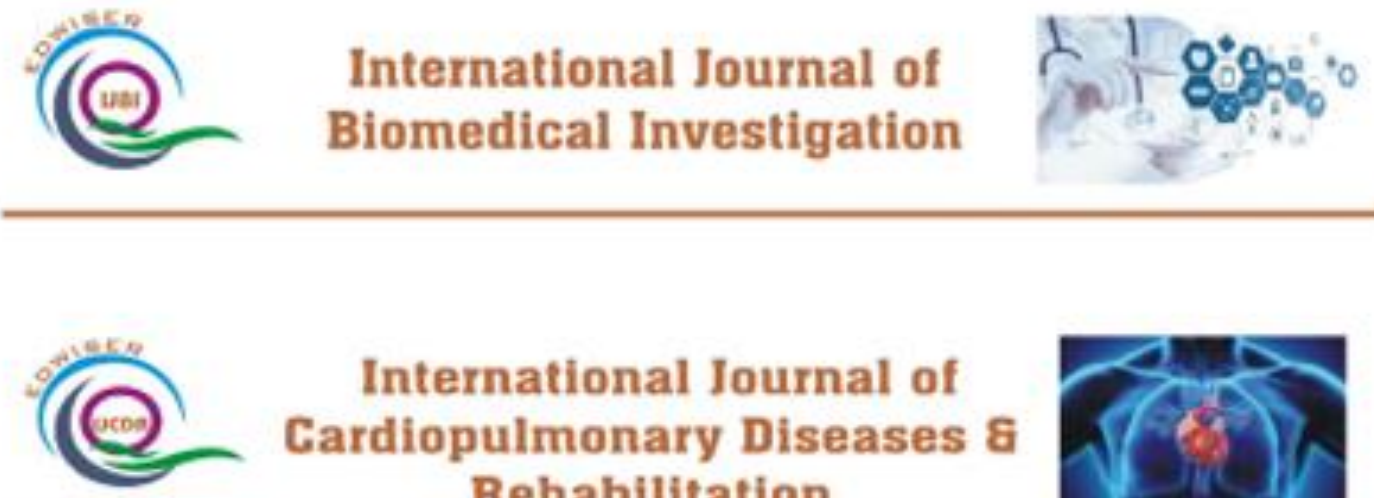

\section{International Journal of Cardiopulmonary Diseases \& Rehabilitation}

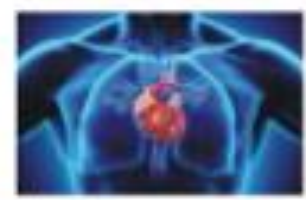

